This is an author produced version of a paper published in Journal of Biosocial Science. This paper has been peer-reviewed but does not include the final publisher proof-corrections or journal pagination.

Citation for the published paper: Lundborg P, Nystedt P, Lindgren B.

"GETTING READY FOR THE MARRIAGE MARKET? THE ASSOCIATION BETWEEN DIVORCE RISKS AND INVESTMENTS IN ATTRACTIVE BODY MASS AMONG MARRIED EUROPEANS." Journal of Biosocial Science, 2006, Issue: Sept 18, pp. 1-14. http://dx.doi.org/10.1017/S0021932006001611

Access to the published version may require journal subscription. Published with permission from: Cambridge University Press 


\section{Getting ready for the marriage market? The association between divorce risks and investments in attractive body mass among married Europeans}

Petter Lundborg ${ }^{1,3}$, Paul Nystedt ${ }^{1,2,4, *}$ and Björn Lindgren ${ }^{1,3,4}$

${ }^{1}$ Lund University Centre for Health Economics (LUCHE), Lund, Sweden;

${ }^{2}$ Department of Economics, Linköping University;

${ }^{3}$ Department of Health Sciences, Lund University, Sweden;

${ }^{4}$ Vårdal Institute, Lund University, Sweden

\section{Summary}

This article explores to what extent married middle-aged individuals in Europe are governed by the risk of experiencing divorce, when shaping their physical appearance. The main result is that divorce risks, proxied by national divorce rates, are negatively connected to Body Mass Index (BMI) among married individuals but unrelated to BMI among singles. Hence, it seems that married people in societies where divorce risks are high are more inclined to invest in their outer appearance. One interpretation is that high divorce rates make married people prepare for a potential divorce and future return to the marriage market.

\footnotetext{
*Author for correspondence

Department of Economics

Linköping University

SE-581 83 Sweden

email: paul.nystedt@eki.liu.se

Phone: (+46) 13281584

Fax: (+46) 13281873
} 


\section{Introduction}

A wide variety of studies have connected the status of being married or having a partner to a range of positive primary outcomes, such as longevity, health, income, wealth and overall life satisfaction (Hu and Goldman, 1990; Coombs, 1991; Joung et al. 1994; Waite and Gallagher, 2000; Van Poppel and Joung, 2001). Spouses may benefit from household economies of scale and specialisation gains as well as supporting each other materially, emotionally and socially, though marriage "selection” rather than "protection” may account for some of the positive correlations (Goldman, 1993; Murray, 2000). Hence, attracting a "high quality" partner seems essential for single individuals, but the success rate is dependent on the individual's own value in the marriage market (Becker, 1974; 1981). Naturally, this value is a complex mixture of characteristics, ranging from e.g. personality, physical attractiveness and health to education, earnings, wealth and social status. Many of these features are determined rather early in life. Genetic predispositions govern significant portions of one’s looks and personality, and most people have completed their formal education well before the age of 30 . The marriage-market literature has focussed on education and wage among rather young people, generally finding positive assortative mating (Lam, 1988; Mare, 1991; Bloch and Ryder, 2000; Nakosteen et al., 2004).

This paper departs from the previous literature by viewing marriage-market related incentives and behaviour from a different angle. Focus is set on; to what extent married middle-aged individuals in Europe are governed by the risk of experiencing divorce, when shaping their physical appearance. The rationale is this: While many other components that determine one's marriage-market value may be rather fixed for middle-aged and older individuals, the body constitution is under the continuous influence of dietary and exercise behaviour. Thus, moderate intake of food and drink and regular physical exercise are options available to 
control one’s BMI as a way to act precautionary in order to stand well prepared for a potential future re-entering into the marriage market.

The norm on what is perceived as an appropriate and attractive body shape varies over time as well as between cultures. During major parts of human history, food has been a scarce resource not exceeding subsistence level by far. Hence, a somewhat "prominent stature” has sometimes been considered desirable since, in contrast to being thin, it signalled wealth as well as good health and fertility. Eligibly, being of considerable size is still viewed as desirable in some cultural settings. For instance, the social recognition and respect of Japanese sumo wrestlers is well known. Among the Annangs of Nigeria, young women traditionally spend time in so called 'fattening rooms' in order to get in shape for attracting a man to marry (Brink, 1995).

During the $20^{\text {th }}$ century, shortage of food has become a lesser problem in the western world and the risk of famines has been virtually eliminated. Since the 1970s, factors, such as decreasing real price of food, lower physical calorie expenditure at work, aggressive marketing and increased establishment of fast food restaurants, have contributed to a development where overweight and obesity, have in fact become an exploding public-health problem (e.g. Philipson, 2001; Chou et al., 2004; James et al., 2001; Helmchen and Henderson, 2004). Hence, the potential positive link between health and a rather massive body constitution has been reversed. Consequently, the current western norm favours slenderness and fitness. Whereas there is a negative association between socio-economic status and body mass in developed societies, at least for women, the opposite is true in developing societies, where the growth of body mass over time has been found to be associated with SES (Ball and Crawford 2005). Attitudes towards obesity and thinness in 
different societies are congruent with these results (Sobal and Stunkard, 1989). Overweight and obesity are associated with negative discrimination in at least three main areas in the western world: employment, education, and health care (Puhl and Brownell, 2001). Obese persons are less healthy and earn less than the general population (Cawley, 2004; Lundborg et al., 2006), they are considered as less preferred dating as well as sexual partners, and less likely to marry (Sobal et al, 1995; Chen and Brown, 2005; Fu and Goldman, 1996).

Overweight and obesity are generally the result of a surplus in the energy balance stemming from excess food intake in relation to the needs. Naturally, the body constitution is under the influence of individual behaviour and, hence, affected by more or less deliberate choices made by the individual over the life-course. Further, forming one's bodily shape in either direction is a rather long-term process. From a traditional health-economics perspective à la Grossman (1972), one may therefore view exercise and dietary behaviour as investments (or disinvestments) in health and attractiveness (Bolin et al., 2006).

The incentives to make the considered health/attractiveness investments in order to gain a high value on the marriage market vary with marital status. Singles face greater expected returns than happily married individuals. However, all marriages do not turn out to be for life, and divorce rates are increasing, yielding a steady influx of formerly married individuals into the marriage market. Indeed, marriage has been found to be associated with weight gains and divorce with weight loss (Jeffery and Rick, 2002). Since weight change is a long-term process, not only single and separating individuals may be concerned about their outer appearance from this respect, but also married individuals have a precautionary motive to be slender and prepared for a potential future as divorced (or widowed for that matter), a motive that increases with the risk of divorce. 
The main purpose of this paper is to analyse whether such a motive may influence married individuals to make health investments resulting in an "appropriate” bodily stature, proxied by their Body Mass Index (BMI). Naturally, it is impossible to measure the actual risks of divorce within individual marriages. Instead, the national divorce rate is used as a proxy for all married people. Singles should be less affected by the national divorce risk as they already are in the marriage market. Thus, the basic theory posed, is that married individuals have some perception of divorce risks on a general basis, and that these risks are negatively correlated with their BMI, whereas there is no such correlation for single individuals.

An alternative, yet similar theory is that the causal link is just the opposite; divorce risks are high in populations where married people continue to compete in the marriage market by keeping themselves in trim. However, both theories are built on the same basic premise; married people are influenced by marriage market conditions and incentives when deciding upon investments in their outer appearance (BMI). Either they live under cultural conditions allowing them to continue to compete in the marriage market, or they prepare themselves as a consequence of high expectations of becoming divorced, hence re-entering the marriage market. Regardless of the exact timing, origin and magnitude of the two possible underlying causal arrows, they both give rise to the same public health related suggestion: Dynamic marriage markets, implied by high divorce rates are associated with low BMI among the married. In other words, the main empirical hypothesis is that the national divorce rate is connected to the BMI of married, but not single, individuals.

Marital life courses and expectations are certainly not the only factors associated with body weight. Socio-economic status captured by occupation or education correlates negatively with 
BMI, obesity prevalence and weight gain in developed societies (Ball and Crawford, 2005;

Matthews et al., 1999). Moreover, labour market status may affect BMI. Being employed may be associated with a more active lifestyle compared to those being unemployed. On the other hand, many jobs are sedimentary, possibly leading to less expenditure of calories. In line with this, Ruhm (2000) found unemployment rates to be negatively related to BMI. Alcohol has a high caloric content but there is mixed evidence as to whether alcohol consumption contributes to weight gain or not (see e.g. Prentice, 1995). Metabolic rates are higher among smokers than among non-smokers; smokers generally weigh less than non-smokers, and quitting smoking is often associated with a weight gain (Klesges et al., 1989; Pinkowish, 1999). BMI has been found to be negatively associated with functional ability, as measured, for instance, through ADL-limitations (Sulander et al., 2005; Kaplan et al., 2003; Ferraro and Booth, 1999). More generally, both functional ability and health limitations may function as barriers to conduct physical exercise, which, in turn, may affect BMI (Ford and Herman, 1995; Ford et al., 2003). There are also results indicating that the above processes may be different for men and women (Williamson and O’Neil, 1998; Sobal, 2004; Cawley et al., 2004; Bolin et al., 2006).

Divorce rates differ among the European countries. The SHARE (Survey of Health, Ageing, and Retirement in Europe) data collection project provides an opportunity to control for the individual factors mentioned above, analysing to what extent Europeans, in their physicalattractiveness investment behaviour, are influenced by their risk of divorce. Data and some descriptive results are presented next, followed by an account of methods used and a report on the results from the multiple-regression analyses. A concluding discussion ends the paper. 


\section{Data}

The Survey of Health, Ageing, and Retirement in Europe (SHARE) data-collection project provides a multidisciplinary and cross-national micro database containing approximately 22,000 Europeans. The first wave of data was collected in 2004. The database contains representative samples from the non-institutionalised population aged 50 and over in respective participating country. Spouses were also interviewed, regardless of age. The 11 countries represent Northern Europe (Denmark and Sweden), Central Europe (Austria, France, Germany, Switzerland, Belgium, and the Netherlands) and Southern Europe (Spain, Italy and Greece). In this study, data from Belgium was not included, since it was not yet collected. The database comprises, inter alia, information on self-reported height and weight, which was used to construct Body Mass Index. The database also contains various healthrelated and socio-economic variables such as self-reported health, physical functioning, cognitive functioning, psychological health, well-being, life satisfaction, current work activity, consumption, and education. As divorce rates are decreasing with high age, the sample used in the analysis was restricted to those below 60 years of age. Moreover, a lower age limit was set at 40 . Consequently, the analyses were performed on individuals between 40 and 60 years of age. This yielded a sample of 6,013 married and 1,124 single individuals. The latter category included 551 never-married and 573 divorced individuals. 265 widowed individuals were not included as remarriage frequencies, especially among widows, has been found to be rather low (Chamie and Nsuly, 1981; Haskey, 1999), which may indicate low participation in the marriage market.

Most married people in the study (aged 40-59) have been married for a long time. Hence, from initially being single, they have adapted to their marital life course when it comes to social roles and dietary and exercise behaviour. 
The design of SHARE follows the design of the U.S. Health and Retirement Study (HRS) and the English Longitudinal Study of Ageing (ELSA). A description of methodological issues can be found in Börsch-Supan and Jürges (2005).

\section{Dependent variable}

The dependent variable addressed in this paper was Body Mass Index (BMI), calculated by dividing weight in kilograms by the square of length in metres. This variable was constructed using the self-reported information on height and weight. In the sample of married people, the average person had a BMI of 26.27 (men: 26.82; women: 25.91). The corresponding figure among singles was 26.09 (men: 26.63; women: 25.64). There was substantial variation in average BMI across countries; see Table 1.

\section{Main explanatory variable}

The main focus is set on the potential association between BMI and divorce risk. A simple indicator of relevant, age-specific (40-59), national divorce rates, in the studied sample, was obtained by dividing the number of divorced by the number of married for each country. This measure was then used as a proxy for general divorce risk; see Table 1. The estimated divorce risk varies quite substantially between the countries involved, providing the desired variation. Clearly, there seems to be a south-north gradient in the divorce risk. In Italy, for instance, the estimated divorce risk was 0.02, while the corresponding figure for Denmark was 0.20. Moreover, there seems to be a general negative association among married between divorce risk and BMI. For instance, Greece had a low divorce risk but a high average BMI, whereas the opposite was true for Denmark.

- Table 1 about here - 


\section{Individual background variables}

Essential background information was included in the form of basic demographic (i.e., age and gender), socio-economic (i.e., years of education and whether the respondent was employed or not), and health-related (number of adverse health symptoms and daily activity limitations together with smoking and alcohol consumption) variables. It should be noted that the inclusion of smoking is made under the assumption that people do not use tobacco consumption as a direct weight control devices. The potential endogeneity problem of including smoking is briefly evaluated in the results section below.

Descriptive statistics are shown in Table 2. Overall, the typical married individual was 53 years old, had 11.3 years of education, and reported 1.1 health symptoms. 25 percent were smokers, 23 percent consumed alcohol daily or almost daily and 64 percent were employed. The singles in the sample were rather similar; the typical single was 54 years old, had 11.8 years of education, and reported 1.3 health symptoms. Moreover, 39 percent were smokers, 21 percent consumed alcohol daily or almost daily and 62 percent were employed. Single women had about one more year of education than married women (12 vs. 11 years), whereas men were less affected by marital status from this respect. There was no gender difference whatsoever in employment among singles (62\% employed) but married men were employed more (76\%) and married women less (56\%). Further, married and single men were smokers to a higher extent and consumed alcohol more frequently than women of respective marital status.

- Table 2 about here - 


\section{Methods}

The demand for an attractive (i.e. low) body mass was specified empirically as:

$B M I_{i}=\mathbf{x}_{\mathrm{i}}{ }^{\prime} \boldsymbol{\beta}+\varepsilon_{i}$

where $\mathrm{BMI}_{i}$ is the BMI of person $i, \mathbf{x}$ is a vector of explanatory variables including the national divorce risk and individual socio-economic and demographic characteristics, $\boldsymbol{\beta}$ is the associated vector of coefficients, and $\varepsilon_{i}$ is the error term. The influence of the exogenous variables on BMI was estimated via ordinary least squares (OLS).

\section{Results}

Firstly, results from the estimation of Eq. 1, regarding individual background variables, are reported. Secondly, the association between divorce risk and BMI, controlling for these individual background variables, is presented. Thirdly, since there may be special doubts about the appropriateness of treating smoking as an exogenous variable, the impact of excluding smoking as an explanatory variable is evaluated. Fourthly, the possibility that any of the found effects are gender dependent is tested.

- Table 3 about here -

\section{Individual background variables}

The first columns of table 3 report the estimated parameters of the estimation of Eq. 1 for the married and single samples respectively. For several individual background variables, the effect on BMI has roughly the same size regardless of marital status: education (-0.11, 0.13), employment (-0.58, -0.36$)$, and number of symptoms $(0.44$ and 0.65$)$ for married and 
singles, respectively). Daily activity limitations affected BMI more strongly among married people (0.64) than among singles (0.26, insignificant). The association between being a smoker and BMI was somewhat stronger for singles (-0.96) than for married (-0.54). Daily or almost daily alcohol consumption showed a similar effect for married (-0.60) and singles (0.61), but were only significant at the 7 percent level in the latter case. The estimated difference in BMI between men and women was roughly equal among married $(-1.47)$ and singles $(-1.37)$.

\section{Divorce risk}

Controlling for these individual effects leaves a marked difference in national divorce-rate effect between the marital statuses (see Table 3). Whereas this rate was negatively associated with BMI for married individuals (-3.28), it was rather unrelated to the BMI of singles $(-0.84$, highly insignificant). Thus, the results suggest that, for married people, an increase in the divorce risk by 0.1 (BMI effect: $0.1 \times-3.28 \approx-0.33$ ) would be associated with a change in BMI similar to that of 3 years additional schooling (BMI effect: $3 \times-0.11 \approx-0.33$ ).

\section{Excluding smoking as an explanatory variable}

The above figures are estimated under the assumption that the explanatory variables are all truly exogenous. Strictly speaking, only age and, maybe, gender are completely exogenous in a lifetime perspective. In a generalised human-capital model, all other individual background variables might be seen, at least partly, as the outcomes of simultaneous and interdependent individual decisions. Available cross-section data does not permit a more sophisticated analysis of this issue, but a somewhat closer look at smoking is taken below. Though smoking is clearly linked to BMI, people probably do not start to smoke primarily in order to lose weight, but fear of gaining weight may prevent smokers from quitting (Pomerleau et al., 
1993). Hence, from the perspective taken here, continuation of smoking could be one mean by which married individuals react to a high divorce risk, ceteris paribus, diminishing the true divorce-risk BMI effect presented above. However, excluding smoking from the estimations only very mildly affect the estimates (the divorce-risk effect would raise from 3.28 to 3.40, and the influence of the other variables on BMI remains virtually unchanged). This suggests that the rather cautious approach taken above, including smoking as an exogenous, healthrelated, lifestyle factor, that affects weight, under the assumption that the decision to smoke in general is not connected to weight concerns, is robust.

\section{Gender differences}

In order to test for gender differences, separate estimations were made for males and females of respective marital status. A statistical evaluation of the significance, of the resulting gender discrepancies, was obtained by adding a gender dummy and interactions between this dummy and all the other variables to the original estimations (of Eq. 1). The results for married individuals of respective sex are presented in the mid columns of table 3. The effect of the divorce risk variable was quite similar for females (-3.2) and males (-3.1), respectively (main effect significant for both husbands and wives, and needless to say, the associated gender interaction term was highly insignificant, $\mathrm{p}$-value $=0.94)$. The only significant interaction

effects were those between gender on the one hand and education and alcohol consumption, respectively, on the other. Education showed a stronger effect on BMI among females $(-0.15)$ than among males (-0.06). The effect of daily or almost daily alcohol consumption on BMI was negative among females (-1.28) and non-existent among males (0.00).

- Table 4 about here - 
Finally, results from regressions for singles of respective sex are reported in the last columns of table 3. None of the considered gender interaction terms were significant, as revealed in the last column of Table 3. However, it could be noted that qualitatively, the estimated parameters of daily alcohol consumption followed the gender pattern found for married, i.e. that the effect was greater for women. In sum, there was no evidence for gender differences in the effect of divorce rate on BMI, neither among married people, nor among singles. Indeed, most variables showed similar associations with BMI for males as well as for females.

- Table 5 about here -

\section{Concluding remarks}

Some comments on the two major limitations of the study are warranted. Firstly, at present there is no panel-data available from the SHARE data collection project, and cross-section data does limit the possibilities for analysis and firm conclusions. Secondly, it should be observed that the national divorce rate was the only nation-specific community variable used, and this rate may well be correlated with other unobserved heterogeneity among the studied countries and, hence, potentially capture other causal mechanisms. However, controlling for a number of individual factors (education etc., correlated with BMI in line with previous empirical research), such mechanisms ought to strike throughout the whole population, affecting people uniformly regardless of e.g. marital status.

That said, this study yielded a rather speculative result. Observed national divorce risks were negatively associated with BMI for married people but virtually uncorrelated with BMI for singles. Hence, it seems that married people in societies where divorce risks are high are more inclined to invest in their outer appearance. One interpretation is that high divorce rates make 
married people prepare for a potential divorce and future return to the marriage market. Another is, of course, that married individuals, especially in societies where divorce is common, perceive that being overweight may affect spousal relations and more easily lead to divorce than where divorce is more unusual. Contradicting this latter line of reasoning, the association among young married U.S. citizens, between overweight and obesity, on the one hand, and marital dissolution, on the other is weak (Fu and Goldman, 2000), whereas there is a negative connection between obesity and the rate at which singles enter marriage (Fu and Goldman, 1996). It could also be that the causal link between national divorce rates and BMI among the married is just the opposite; married populations continuing to compete in the marriage market, by keeping themselves fit, resulting in high divorce rates. Nevertheless, this suggestion is also based on the fundamental idea that marriage market conditions govern the attractiveness investment behaviour of married people. The potential relative strength of any underlying causal arrows going in opposite directions is hard to assess from both theoretical as well as empirical perspectives. From a broader standpoint, any inter-relation between BMI and divorce rates may be viewed as a part of the continuous, dynamic process in which individual behaviour, institutions and norms interact to form the culture of society. A growing literature deals with the role of economic and non-economic incentives in explaining the rise in average BMI experienced in most western countries (e.g. Philipson, 2001; Chou et al., 2004). In parallel, marriage market studies have been conducted, focussing on assortative mating and matching processes among individuals of different attributes, mainly regarding education and earnings (e.g. Nakosteen et al., 2004). However, no prior studies have concerned the marriage market-related incentives for married individuals of maintaining an attractive physical appearance generated by the increase in divorce rates experienced in most western countries. The results obtained in this study, indicate that international variation of divorce risks may explain some of the spatial differences in average 
BMI observed across otherwise quite similar nations. In fact, the results suggest that the increase in overweight and obesity experienced in most western countries would actually have been greater, had the same countries not experienced a simultaneous increase in divorce rates reflecting a more dynamic marriage market.

Further research should aim at analysing the relationship between divorce risk and BMI using other proxies of divorce risk than the one used in the present study. Using measures of divorce risk at more disaggregated levels, such as neighbourhoods, for instance, may be one option. Moreover, the usage of panel-data would allow for better controls of unobserved variables being correlated both with BMI and divorce risks. Among the characteristics determining the value in the marriage market from a dynamic perspective, BMI has the advantage of being comparatively changeable over the lifecycle and under the direct influence of individual choices and behaviour. After all, it is impossible to e.g. decrease one's educational level and rather few above the age of 40 engage in formal schooling. Hence, BMI may serve as a mirror into how marriage market related incentives affect the behaviour of middle-aged individuals. 


\section{References}

Ball, K., Crawford, D. (2005) Socioeconomic status and weight change in adults: a review. Social Science and Medicine 60, 1987-2010.

Becker, G. S. (1974) A Theory of Marriage. In Schultz, T.W. (ed) Economics of the Family. University of Chicago Press, Chicago, pp. 299-344.

Becker, G.S. (1981) A Treatise on the Family. Harvard University Press, Cambridge.

Bloch, F., Ryder, H. (2000) Two-sided search, marriages and matchmakers. International Economic Review 41, 93-115.

Bolin, K., Lindgren, B., and Rössner, S. (2006) The significance of overweight and obesity for individual health behaviour. Forthcoming: Scandinavian Journal of Public Health.

Brink, P. J. (1995) The fattening room among the annang of Nigeria. In Pollock, N. J., de Garine, I. (eds) Social Aspects of Obesity. Gordon and Breach, New York..

Börsch-Supan, A., Jürges, J. (eds) (2005) Health, Ageing and Retirement in Europe - Methodology. Mannheim Research Institute for the Economics of Ageing.

Cawley, J. (2004) The impact of obesity on wages. Journal of Human Resources XXXIX, 451-474.

Cawley, J., Markowitz, S., Tauras, J. (2004) Lighting up and slimming down: The effects of body weight and cigarette prices on adolescent smoking initiation. Journal of Health Economics 23, 293-311.

Chamie, J., Nsuly, S. (1981) Sex differences in remarriage and spouse selection. Demography 18, 335-348.

Chen, E. Y., Brown, M. (2005) Obesity stigma in sexual relationships. Obesity Research 13, 13931397.

Chou, S.Y., Grossman, M., Saffer, H. (2004) An economic analysis of adult obesity: Results from the behavioral risk factor surveillance system. Journal of Health Economics 23, 565-587.

Coombs, R. H. (1991) Marital status and personal well-being: A literature review. Family Relations 40, 97-102.

Ferraro, K. F., Booth, T. L. (1999) Age, body mass index, and functional illness. Journal of Gerontology: Social Sciences 54B, 339-S348.

Ford, E.S., Heath, G.W., Mannino, D.M., Redd, S.C. (2003) Leisure-time physical activity patterns among US adults with asthma. Chest 124, 432-7.

Ford, E. S, Herman, W. H. (1995) Leisure-time physical activity patterns in the U.S. diabetic population. Findings from the 1990 National Health Interview Survey--Health Promotion and Disease Prevention Supplement. Diabetes Care 18, 27-33. 
Fu, H., Goldman, N. (1996) Incorporating health into marriage choice models: demographic and sociological perspectives. Journal of Marriage and the Family 58, 740-758.

Fu, H., Goldman, N. (2000) The association between health-related behaviours and the risk of divorce in the US. Journal of Biosocial Science 32, 63-88.

Goldman, N. (1993) Marriage selection and mortality patterns: Inferences and fallacies. Demography 30, 189-207.

Grossman, M. (1972) On the concept of health capital and the demand for health. Journal of Political Economy 80, 223-255.

Haskey, J. (1999) Divorce and remarriage in England and Wales. Population Trends 95, 1822.

Helmchen, L. A., Henderson, R. M. (2004) Changes in the distribution of body mass index of white US men, 1890-2000. Annals of Human Biology 31, 174-181.

Hu, Y., Goldman, N. (1990) Mortality differentials by marital status: An international comparison. Demograpby 27, 233-250.

James, P., Leach, R., Eleni, K., Shayeghi, M. (2001) The worldwide obesity epidemic. Obesity Research 9, supp 4, 228-233.

Jeffery, R. W., Rick, A. M. (2002) Cross-sectional and longitudinal associations between body mass index and marriage-related factors. Obesity Research 10, 809-15.

Joung, I., Van De Mheen, H., Stronks, K., Van Poppel, F., Mackenbach, J. P. (1994) Differences in self-reported morbidity by marital status and by living arrangement. International Journal of Epidemiology 23, 91-97.

Kaplan, M. S., Huguet, N., Newsom, J. T., McFarland, B. H., Lindsay, J. (2003) Prevalence and correlates of overweight and obesity among older adults: findings from the Canadian National Population Health Survey. Journal of Gerontology: Medical Sciences 58A, 10181030.

Klesges, R., Meyers, A., Klesges, L., LaVasque, M. (1989) Smoking, body weight, and their effects on smoking behavior: A comprehensive review of the literature. Psychological Bulletin 106, 204-230

Lam, D. (1988) Marriage markets and assortative mating with household public goods: Theoretical results and empirical implications. Journal of Human Resources 23, 462-487.

Lundborg, P., Lindgren, B., Höjgård, S., Bolin, K. (2006) Obesity and labour market outcomes among the elderly in Europe. In: Bolin, K., Cawley, J.(eds.). Advances in health economics and health services research Volume 17: The economics of obesity. New York: Elsevier. Forthcoming.

Mare, D. (1991) Five decades of educational assortative mating. American Sociological Review 56, 15-32. 
Matthews, S., Manor, O., Power, C. (1999) Social inequalities in health: are there gender differences? Social Science \& Medicine 48, 49-60.

Murray, J. (2000) Marital protection and marital selection: Evidence from a historicalprospective sample of American men. Demography 37, 511-521.

Nakosteen, R., Westerlund, O., Zimmer, M. (2004) Matching and earnings: evidence from the unmarried population in sweden. Journal of Human Resources, 39:1033-44.

Philipson, T. (2001) The world-wide growth in obesity: an economic research agenda. Health Economics 10, 1-7.

Pinkowish, M. D. (1999) Hand in glove: smoking cessation and weight gain. Patient Care 33, 134.

Pomerleau, C. S., Ehrlich, E., Tate, J. C., Marks, J. L., Flessland, K.A., Pomerleau, O.F. (1993) The female weight-control smoker: A profile. Journal of Substance Abuse 5, 391-400.

Prentice, A. M. (1995) Alcohol and obesity. International Journal of Obesity 19, 44-50.

Puhl, R., Brownell, K. (2001) Bias, discrimination, and obesity. Obesity Research 9, 788-805.

Ruhm, C. (2000) Are recessions good for your health? Quarterly Journal of Economics 115, 617-650.

Sobal, J. (2004) Sociological analysis of the stigmatisation of obesity. In Germov, J., Williams, L. (eds) A Sociology of Food and Nutrition: The Social Appetite. $2^{\text {nd }}$ edition. John Wiley, Melbourne.

Sobal, J., Stunkard, A. J. (1989) Socioeconomic status and obesity: A review of the literature. Psychological Bulletin 105, 260-275.

Sobal, J., Nicolopoulos, V., Lee, J. (1995) Attitudes about overweight and dating among secondary school students. International Journal of Obesity and Related Metabolic Disorders 19, 376-81.

Sulander, T., Martelin, T., Rahkonen, O., Nissinen, A., Uutela, A. (2005) Associations of functional ability with health-related behavior and body mass index among the elderly. Archives of Gerontology and Geriatrics 40, 185-199

Waite, L. J., Gallagher, M. (2000) The Case for Marriage: Why Married People are Happier, Healthier, and Better off Financially. Harvard University Press, Cambridge, Massachusetts.

Williamson, D.A., O’Neil, P.M. (1998) Behavioral and psychological correlates of obesity. In Bray, G. A., Bouchard, C., James, W. P. T. (eds) Handbook of Obesity. Marcel Dekker, New York.

Van Poppel, F., Joung, I. (2001) Long-term trends in marital status mortality differences in the Netherlands 1850-1970. Journal of Biosocial Science 33, 279-303. 


\section{Acknowledgements}

This paper uses data from the early release 1 of SHARE 2004. This release is preliminary and may contain errors that will be corrected in later releases. The SHARE data collection has been primarily funded by the European Commission through the 5th framework programme (project QLK6-CT-2001-00360 in the thematic programme Quality of Life programme area). Additional funding came from the US National Institute on Aging (U01 AG09740-13S2, P01 AG005842, P01 AG08291, P30 AG12815, Y1-AG- 4553-01 and OGHA 04-064). Data collection in Austria (through the Austrian Science Foundation, FWF), Belgium (through the Belgian Science Policy Administration) and Switzerland (through BBW/OFES/UFES) was nationally funded. The SHARE data set is introduced in Börsch-Supan et al. 2005; methodological details are contained in Börsch-Supan and Jürges 2005. Additional funding for the Swedish participation in the SHARE data collection project came from the Bank of Sweden Tercentenary Foundation, the Swedish Council for Working Life and Social Research, and the Swedish Social Insurance Agency. The research reported in this paper was supported by a grant from the Swedish Council for Working Life and Social Research, which is gratefully acknowledged. 


\section{Tables}

Table 1. Divorce risk and average BMI among married across countries in the studied sample.

\begin{tabular}{lcc}
\hline Country & Divorce risk & Average BMI among married (sd) \\
\hline Northern Europe & & \\
Sweden & 0.11 & $25.66(3.87)$ \\
Denmark & 0.20 & $25.52(4.02)$ \\
Central Europe & & \\
Austria & 0.14 & $27.00(4.44)$ \\
Germany & 0.08 & $26.41(4.42)$ \\
Netherlands & 0.06 & $26.17(4.17)$ \\
France & 0.12 & $25.64(4.66)$ \\
Switzerland & 0.13 & $25.25(4.26)$ \\
Southern Europe & & \\
Spain & 0.02 & $27.30(4.52)$ \\
Italy & 0.02 & $26.39(4.47)$ \\
Greece & 0.05 & $26.83(4.12)$ \\
& & \\
Total & 0.08 & $26.28(4.32)$ \\
\hline
\end{tabular}


Table 2. Descriptive statistics. Mean (standard deviation within parenthesis).

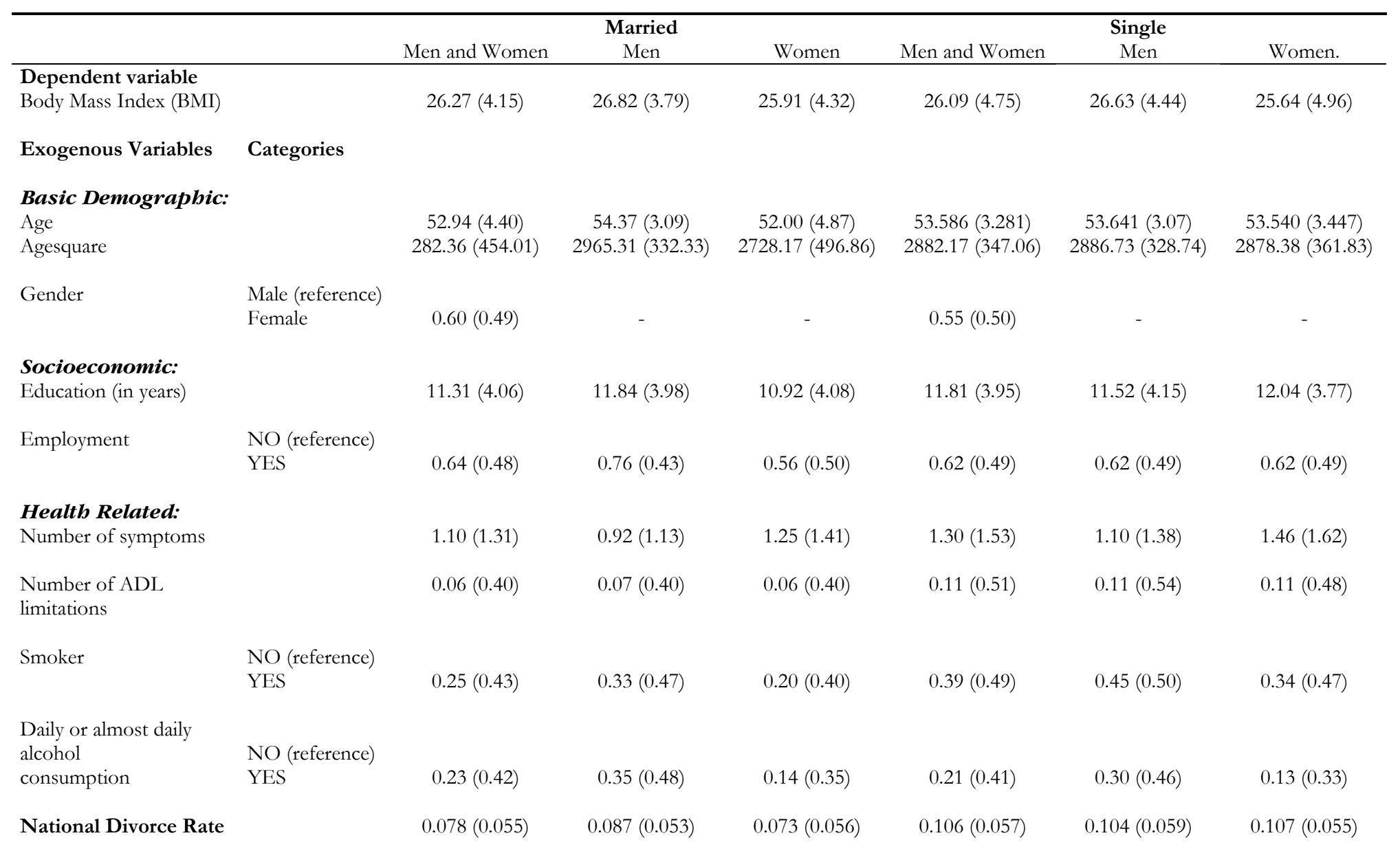


Table 3. Results from multivariate OLS regressions on BMI.

\begin{tabular}{|c|c|c|c|c|c|c|c|c|c|c|c|c|c|c|c|}
\hline \multirow[b]{2}{*}{ Exogenous Variables } & \multirow[b]{2}{*}{ Categories } & \multicolumn{2}{|c|}{$\begin{array}{l}\text { Married } \\
\text { Men and Women }\end{array}$} & \multicolumn{2}{|c|}{$\begin{array}{l}\text { Single } \\
\text { Men and Women }\end{array}$} & \multicolumn{2}{|c|}{ Married Men } & \multicolumn{2}{|c|}{ Married Women } & \multirow{2}{*}{$\begin{array}{l}\text { Gender } \\
\text { difference } \\
\text { in effect } \\
\text { for married }\end{array}$} & \multicolumn{2}{|c|}{ Single Men } & \multicolumn{2}{|c|}{ Single Women } & \multirow{2}{*}{$\begin{array}{l}\text { Gender } \\
\text { difference in } \\
\text { effect for } \\
\text { singles }\end{array}$} \\
\hline & & Coeff. & $\mathrm{p}$-value & Coeff. & p-value & Coeff. & $\mathrm{p}$-value & Coeff. & $\mathrm{p}$-value & & Coeff. & p-value & Coeff. & $\mathrm{p}$-value & \\
\hline Constant & & 7.99 & 0.34 & 30.06 & 0.15 & 21.72 & 0.20 & 11.04 & 0.28 & & 11.63 & 0.81 & 43.00 & 0.08 & \\
\hline \multicolumn{16}{|l|}{ Basic Demographic: } \\
\hline \multirow{2}{*}{ Gender } & Male (reference) & & & & & & & & & & & & & & \\
\hline & Female & -1.47 & 0.00 & -1.37 & 0.00 & & & & & & & & & & \\
\hline Age & & 0.78 & 0.01 & -0.15 & 0.85 & 0.28 & 0.66 & 0.60 & 0.13 & 0.67 & 0.60 & 0.74 & -0.75 & 0.93 & 0.50 \\
\hline Agesquare & & -0.01 & 0.02 & -0.00 & 0.77 & 0.00 & 0.60 & -0.01 & 0.17 & 0.76 & -0.01 & 0.74 & 0.01 & 0.35 & 0.46 \\
\hline \multicolumn{16}{|l|}{ Socioeconomic: } \\
\hline Education (in years) & & -0.11 & 0.00 & -0.13 & 0.00 & -0.06 & 0.00 & -0.15 & 0.00 & 0.00 & -0.15 & 0.01 & -0.11 & 0.06 & 0.69 \\
\hline \multirow[t]{2}{*}{ Employment } & NO (reference) & & & & & & & & & & & & & & \\
\hline & & -0.58 & 0.00 & -0.36 & 0.24 & -0.43 & 0.03 & -0.61 & 0.00 & 0.51 & 0.17 & 0.68 & -0.77 & 0.08 & 0.12 \\
\hline \multicolumn{16}{|l|}{ Healtb Related: } \\
\hline Number of Symptoms & & 0.44 & 0.00 & 0.65 & 0.00 & 0.42 & 0.00 & 0.43 & 0.00 & 0.90 & 0.71 & 0.00 & 0.62 & 0.00 & 0.70 \\
\hline $\mathrm{ADL}$ & & 0.64 & 0.00 & 0.26 & 0.70 & 0.35 & 0.24 & 0.88 & 0.00 & 0.18 & -0.11 & 0.91 & 0.64 & 0.47 & 0.56 \\
\hline \multirow[t]{2}{*}{ Smoker } & NO (reference) & & & & & & & & & & & & & & \\
\hline & YES & -0.54 & 0.00 & -0.96 & 0.00 & -0.40 & 0.01 & -0.58 & 0.00 & 0.46 & -1.01 & 0.01 & -0.90 & 0.03 & 0.84 \\
\hline $\begin{array}{l}\text { Daily or almost daily } \\
\text { alcohol consumption }\end{array}$ & $\begin{array}{l}\text { NO (reference) } \\
\text { YES }\end{array}$ & -0.60 & 0.00 & -0.61 & 0.07 & 0.00 & 1.00 & -1.28 & 0.00 & 0.00 & -0.38 & 0.36 & -0.82 & 0.16 & 0.53 \\
\hline National Divorce Rate & & -3.28 & 0.00 & -0.84 & 0.73 & -3.06 & 0.03 & -3.21 & 0.04 & 0.94 & -0.93 & 0.78 & -0.23 & 0.95 & 0.88 \\
\hline Observations & & 6,013 & & 1,124 & & 2,584 & & 3,429 & & & 511 & & 613 & & \\
\hline
\end{tabular}

